\title{
EVALUATION OF COLOR CHANGE OF HEAT CURED DENTURE BASE MATERIAL INCORPORATED WITH NOVEL SILVER NANOPARTICLES SUBMITTED TO ACCELERATED AGING
}

\author{
Hamada Zaki Mahross*
}

\begin{abstract}
Purpose: To investigate and compare the influences of adding different concentrations of colloidal forms silver nanoparticles on color changes of heat cured acrylic resin denture base material submitted to Accelerated aging.

Methods: A total of 40 disc-shaped specimens were prepared from heat cured PMMA resins with different concentration of silver nanoparticles. The specimens were divided into 4 groups according to the addition of colloidal form of silver nanoparticles (NAg) percentage (1\%, $2 \%$ and $5 \%$ vol.) which added to the liquid of resin $(\mathrm{n}=10)$; Group I heat cured control group without additives and Groups (II, III and IV) with (1\%, 2\% and 5\%) additives, respectively. All test group specimens were initially measured for color alteration and after each period of accelerated aging stages $252 \mathrm{H}$ (stage I), 504H (stage II), and $1008 \mathrm{H}$ (stage III). A double beam ultra-violet visible spectrophotometer was used to obtain diffuse reflectance data at every $5 \mathrm{~nm}$ between $400-700 \mathrm{~nm}$. The results were recorded using a computer color matching system (CCM) and tabulated for the statistical analysis of the color differences $(\Delta \mathrm{E})$ data. Comparisons between the different studied groups were analyzed using F-test (ANOVA) and Post Hoc test (Scheffe) for pair-wise comparisons. Significance of the obtained results was judged at the significance level of $\alpha=0.05$.
\end{abstract}

Results: All groups of heat-cured acrylic resin with the addition of (NAg) groups II, III and IV were showed significant $(\Delta \mathrm{E})$ values more than group I at initial and at stage I, II of accelerated aging records. In stage III only group IV was showed significant $(\Delta \mathrm{E})$ values more than group I of the same stage. Therefore, group IV was showed significantly highest mean $(\Delta \mathrm{E})$ value followed by group III then group II $(\mathrm{P}<0.05)$ in all accelerated aging stages but group I was showed significantly lowest mean $(\Delta \mathrm{E})$.

Conclusion: The silver nanoparticles incorporation within the acrylic denture base material can change its color. The higher incorporation of silver nanoparticles with accelerated aging, the more color difference values $(\Delta \mathrm{E})$ of the acrylic resin denture.

KEYWORDS: Silver nanoparticles, Color change, Acrylic resin denture, Accelerated aging.

* Assistant Professor of Removable prosthodontics, Faculty of Dental Medicine, Al-Azhar University Cairo, Egypt. 


\section{INTRODUCTION}

In reality, the heat cured acrylic resins PMMA are the most popular material of choice for removable dentures fabrication because it has low cost, pleasant aesthetic properties, adequate strength, low water sorption, low solubility, low thermal conductivity, free from toxicity, reproduce surface details and required relative ease of manipulation and construction methods ${ }^{[1,2]}$. However, it is not the ideal material in every aspect as the denture base polymers should have a good esthetic and smooth glassy surface and should be capable of matching the natural appearance of the soft tissue but discoloration of acrylic resin results in esthetic problems ${ }^{[1,3]}$.

The color and translucency of heat cured resin should be maintained during processing and not stained or change its color during clinical use. Therefore, color stability is an important factor for many dentures materials and color change may be an indicator of aging or damaging of materials. So, it may be the most important clinical factor of prosthesis for determining the patient acceptance $^{[3-5]}$.

The color change of a polymeric material may be caused by intrinsic and extrinsic factors. The intrinsic factors involve resin discoloration itself and matrix changes, occurring during the aging process of the material due to many physical and chemical conditions. But the extrinsic factors such as thermal changes, stain accumulation, artificial dyes, cleaning procedures, and handling by the patient ${ }^{[4,6]}$.

Currently, Silver nanoparticles (NAg) have been applied in several areas of dentistry as endodontics, dental prostheses, implantology and restorative dentistry. Incorporation of NAg aims to avoid or at least to decrease the microbial colonization over dental materials, increasing oral health levels and improving life quality ${ }^{[7-10]}$. Renewed interest has arisen in manufactured silver nanomaterial because of their unusually enhanced physicochemical properties and biological activities compared to the bulk parent materials. Silver nanomaterial has a lots of peculiar and exciting physical and chemical properties that are different from massive silver, so the synthesis and applications of silver nanomaterials have attracted a great deal of attention in the last decade ${ }^{[11,12]}$.

Respecting to manufacture, all kinds of silver nanomaterials with different shapes and sizes were synthesized by many ingenious methods including Nano-rods, Nano-wires, Nano-tubes, Nano-prisms, Nano-plates, Nano-disks, Nano-spheres and Nanopolyhedrons, etc. Silver nanomaterials have exhibited extensive application prospects in many fields especially in biomedical aspect and have already used in everyday consumer products. Although, more biomedical applications of silver nanomaterials still need to be exploited for the future and the biological safety of silver nanomaterials also should be paid enough attention before their practical applications ${ }^{[12,13]}$.

Generally, Acrylic resin is colorless and transparent at a normal temperature/ pressure values. The addition of Nano-silver to heat cured acrylic resin as a measure against odor, bacterial proliferation and to enhance the strength and radioopacity. The thermal and mechanical properties have been studied, but undesirable color changes submitted to accelerated aging have tended to occur ${ }^{[14-16]}$.

So, the purpose of this study was to evaluate and compare the effect of adding different concentrations nanoparticles of silver on color change of acrylic resin denture base material submitted to accelerate aging.

\section{MATERIALS AND METHODS}

A total of 40 disk-shaped specimens $(15 \mathrm{~mm}$ in diameter and $2 \mathrm{~mm}$ in thickness) were prepared from heat cured PMMA resin (Ecocryl - Hot protechno, 
Girona, Spain) figure 1. The specimens were constructed by investing disk-shaped wax pattern (Cavex- Holland BV) of the same dimensions in dental stone III (LabStone- Dentsply, USA) by a conventional flasking procedure in dental flasks. According to Monteiroetal.(2012), ${ }^{[17]}$ Nanoparticles of silver (NAg) in the form of colloidal solution was prepared and added to the monomer of acrylic resin measured by volume proportion with concentration of $(1 \%, 2 \%$ and $5 \%)$ to form a mixture. After dewaxing, the flask retrieved and the acrylic PMMA was mixed in accordance with the manufacturer's instructions and packed then processed at $100^{\circ} \mathrm{C}$ for 45 minutes. After processing, the flask was cooled at room temperature for 30 minutes then opened to remove the specimens.

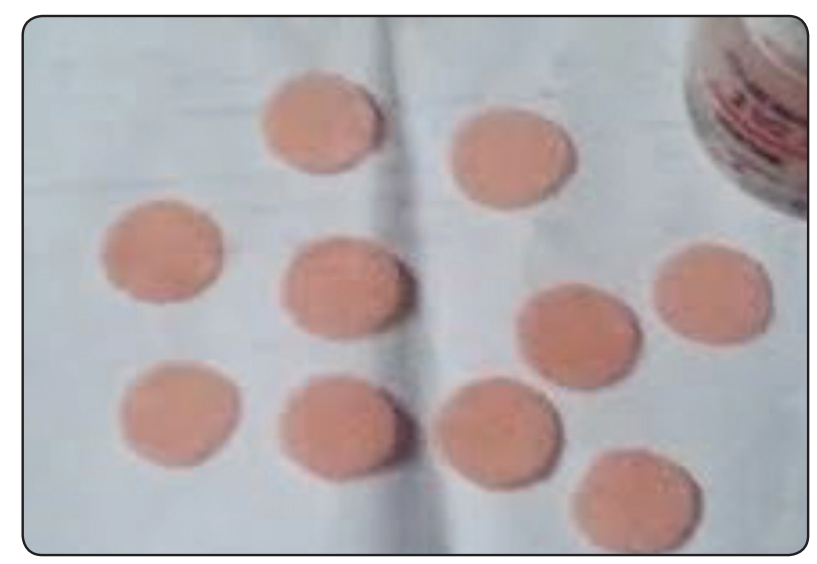

Fig. (1) disk specimen for color stability test.

The specimens were divided into four groups according to the addition of silver nanoparticles (NAg) percentage $(n=10)$ : Group I: heat cured control specimens without additives and Group II, III and IV: heat cured specimens with $1 \%, 2 \%$ and $5 \%$ of NAg, respectively.

All test group specimens were initially measured for color alterations and after each period of accelerated aging stages $252 \mathrm{H}$ (stage I), $504 \mathrm{H}$ (stage II), and $1008 \mathrm{H}$ (stage III) according to ASTMG 53 Standards for non-metallic bodies UVB/condensation (2008). The test specimens were incubated in accelerated aging chamber (Equilam Ind. Co., Diadema, SP, Brazil) then cleaned with water and soap before each reading.

A double beam ultra-violet visible spectrophotometer (U.V-Vis. UV 3101 PC, Shimadzu scanning spectrophotometer, Japan) was used to obtain diffuse reflectance data at every $5 \mathrm{~nm}$ between 400 $-700 \mathrm{~nm}$. An equipped ISR-260 integrating sphere attachment was used for the measurement. The attachment was installed in the spectrophotometer according to the manufacturer's recommendation by using the supplied white calibration standard which used in the reference port for calibration of zero and $100 \%$ reflectance to obtain data. A special sample holder was used to hold the sample in the attachment. Tristimulus value ( $\mathrm{X}, \mathrm{Y}$ and $\mathrm{Z}$ ) was computed relative to the CIE 1985 Commission Internacionale L'Eclairage ${ }^{[18]}$ and relative to particular light source.

According to ANSI /ADA Specification No.80, the ratio of each tristimulus value of a color to their sum was called chromatically coordinate ( $x, y$ and z) i.e.:

$$
\begin{aligned}
& x=X /(X+Y+Z) \\
& y=Y /(X+Y+Z) \\
& z=(1-[X+Y])
\end{aligned}
$$

A CIE three dimensional $\mathrm{L}^{*}, \mathrm{a}^{*}$ and $\mathrm{b}^{*}$ color order system was provided a useful standardization method for color difference assessment. Difference $\Delta \mathrm{E}$ between two colors was determined from the color difference formula:

$$
\Delta \mathrm{E}\left(\mathrm{L}^{*}, \mathrm{a}^{*} \text { and } \mathrm{b}^{*}\right)=\left[(\Delta \mathrm{L})^{2}+(\Delta \mathrm{a})^{2}+(\Delta \mathrm{b})^{2}\right]^{1 / 2}
$$

Where $\mathrm{L}^{*}, \mathrm{a}^{*}$ and $\mathrm{b}^{*}$ depended on tristimulus values $(\mathrm{X}, \mathrm{Y}, \mathrm{Z})$ of the specimens and a perfectly white object where $L^{*}$ corresponds to the value in the Munsell system which represents the lightness coordinate, while $\mathrm{a}^{*}$ is the red-green coordinates and $b^{*}$ is the yellow-blue coordinate. 
The color of each opposing pair is indicated by [the positive and negative values of $a^{*}$ and $b^{*}$ $\left(+\mathrm{a}^{*}=\right.$ redness, $-\mathrm{a}^{*}=$ greenness, $+\mathrm{b}^{*}=$ yellowness, $-b^{*}=$ blueness $)$. The tristimulus values $(\mathrm{X}+\mathrm{Y}+\mathrm{Z})$, the chromatically coordinate $(x, y, z)$, The $L^{*}, a^{*}$ and $b^{*}$, $\Delta \mathrm{E}, \Delta \mathrm{L}, \Delta \mathrm{a}$, and $\Delta \mathrm{b}$ were automatically calculated. The results were recorded using a computer color matching system (CCMS) and tabulated for the statistical analysis of the data. Quantitative data were described using mean and standard deviation of the color difference $\Delta \mathrm{E}$ summation.

\section{Statistical analysis}

Comparisons between the different studied groups were analyzed using One-Way analysis of variance ANOVA followed by Post Hoc test (Scheffe) for pair-wise comparisons. Significance of the obtained results was judged at the significance level of $\alpha=0.05$.

\section{RESULTS}

Comparisons between mean and standard deviation of color differences $(\Delta E)$ values for different test groups with different stages of accelerated aging were shown in Table 1.

The statistical analysis for initial records shown that, in comparison between the test groups ( 1 1) there were a significant difference between the nanosilver groups (II, III and IV) with the control group (I) and between different concentrations of nanosilver group IV with II and III but there was no significance between groups II and III. From the statistical analysis, the same results were recorded in stage I and II of accelerated aging. In stage III, there were significance differences between groups IV with all other groups, but there was no significance between groups II, III with the control group I (Figure 2).

TABLE (1): Comparison between mean color different $(\Delta \mathrm{E})$ values of the tested groups with different stages of accelerated aging.

\begin{tabular}{|l|c|c|c|c|c|}
\hline Test groups & Group I & Group II & Group III & Group IV & $\mathbf{p}_{\mathbf{1}}$ \\
\hline Initial record & $0.40 \pm 0.23$ & $1.37^{\mathrm{a}} \pm 0.52$ & $1.59^{\mathrm{a}} \pm 0.26$ & $2.63^{\mathrm{abc}} \pm 0.28$ & $<0.001^{*}$ \\
\hline Stage I & $0.53 \pm 0.26$ & $1.44^{\mathrm{a}} \pm 0.53$ & $1.82^{\mathrm{a}} \pm 0.36$ & $4.12^{\mathrm{abct}} \pm 0.59$ & $<0.001^{*}$ \\
\hline Stage II & $2.51^{\#} \pm 0.42$ & $3.28^{\mathrm{a}} \pm 0.67$ & $3.47^{\mathrm{a}} \pm 0.27$ & $5.03^{\mathrm{abct}} \pm 0.57$ & $<0.001^{*}$ \\
\hline Stage III & $3.05^{\#} \pm 0.78$ & $3.76^{\#} \pm 0.44$ & $3.81^{\#} \pm 0.50$ & $5.82^{\mathrm{abc} \#} \pm 0.60$ & $<0.001^{*}$ \\
\hline $\mathbf{p}_{2}$ & $<0.001^{*}$ & $<0.001^{*}$ & $<0.001^{*}$ & $<0.001^{*}$ & \\
\hline
\end{tabular}

$p_{1}$ : p value (ANOVA), Sig. bet. groups were performed using Post Hoc Test (Scheffe).

$p_{2}: p$ value (ANOVA) with repeated measures for comparing different stages, Sig. bet. Stages were performed using Bonferroni adjusted.

a: Significant with control

b: Significant with $1 \% \mathrm{NAg}$

c: Significant with $5 \% \mathrm{Nag}$

\#: Significant between initial record with each other stage

*: Statistically significant at $p \leq 0.05$ 


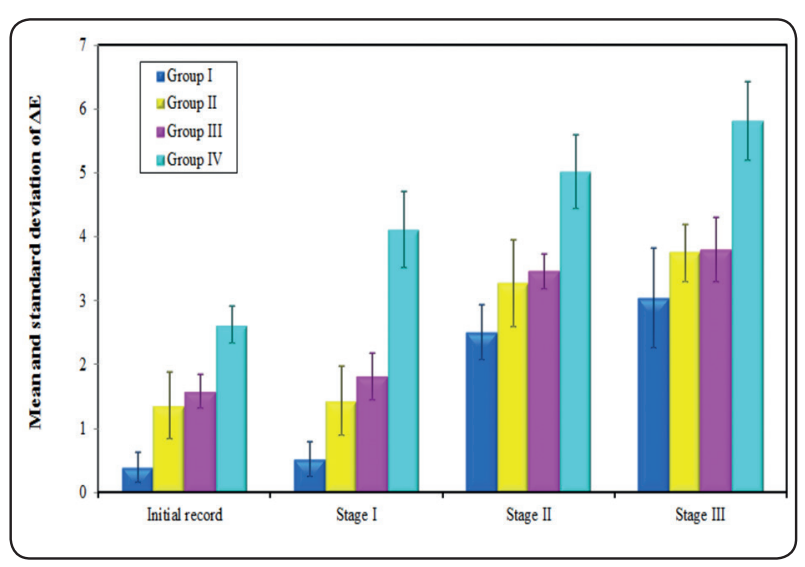

Fig. (2) Mean and standard deviation of color difference values $(\Delta E)$ of different stages of accelerated aging with different tested groups.

The statistical analysis for comparing each group in different stages (significance between Stages, P2) with initial record shown that, for group I there was significant difference in stage II and III but has no significance in stage I, the similar results have been recorded with group II and III in the same stages. For group IV there was significance difference in all stages with initial and with other groups (Figure 3).

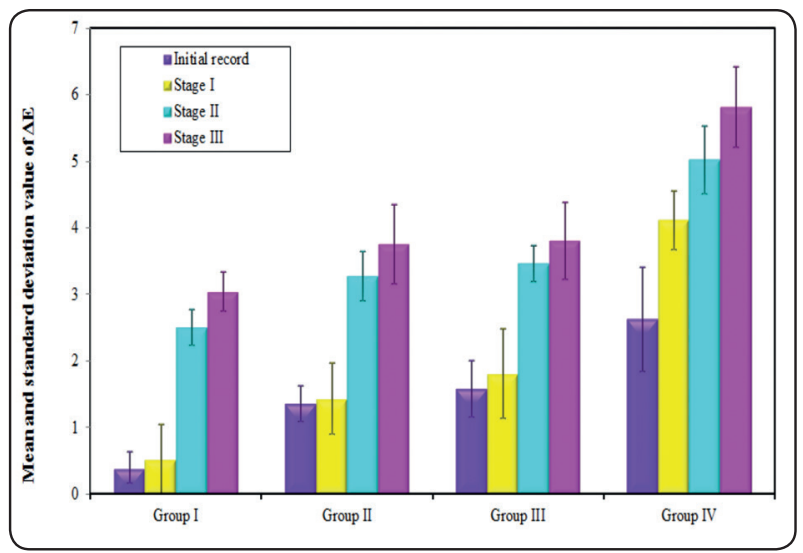

Fig. (3) Mean and standard deviation of color difference values $(\Delta \mathrm{E})$ of the different tested groups with different stages of accelerated aging.

Consequently, all groups of heat-cured acrylic resin (Groups II, III and IV) with the addition of nanoparticles of silver (NAg) were showed significant color differences $(\Delta \mathrm{E})$ values more than control group (Group I) at initial and at stage I, II of accelerated aging records. In stage III only group IV was showed significant color differences $(\Delta \mathrm{E})$ values more than control group (Group I) of the same stage but there was no significance with group II and III.

Heat-cured acrylic resin with 5\% nanoparticles of silver (group IV) was showed significantly highest mean color differences $(\Delta \mathrm{E})$ followed by heat-cured acrylic resin with $2 \%$ nanoparticles of silver (group III) then heat-cured acrylic resin with $1 \%$ nanoparticles of silver (group II) $(\mathrm{P}<0.05)$ in all accelerated aging stages. Heat-cured acrylic resin control group without additives (Group I) was showed significantly lowest mean color differences $(\Delta \mathrm{E})$. The results of color difference values $(\Delta \mathrm{E})$ were showed significant differences $(\mathrm{P}<0.05)$ between groups (II, III and IV) and group I.

\section{DISCUSSION}

Nanotechnology is the most promising field for generating new applications in medicine and dental practice. However, there are few Nano-products currently in use for these purposes and the most prominent type is nanosilver particles which are generally smaller than $100 \mathrm{~nm}$ and contain 20-15,000 silver atoms. At Nano-scale, silver can exhibit remarkably unusual physical, chemical and biological properties and due to its strong antibacterial activity, it was utilized in antibacterial coatings on dental materials and devices to reduce infection rates ${ }^{[19-21]}$. For these community and applicability of nanosilver in dental field it was chosen to be tested in the present study.

The use of nanosilver powder particles has been more preferred than silver particle because the nanoparticles cause better processing and smoother surfaces than the silver powder ${ }^{[15]}$. These results were not coincidence with some authors advising the use of NAg in colloidal form with the monomer of acrylic resin because NAg was shown to possess potent antibacterial properties. Chemically, their smaller particle size and larger surface area could enable them to release more $\mathrm{Ag}$ ions at a low filler 
level, thereby reducing Ag particle concentration necessary for its efficacy and avoiding negative influence on mechanical properties. The Ag ions in the resin agglomerated to form nanoparticles that became part of the resin as the smaller the diameter of the particle, the better the particle distribution and dispersion in the polymer mass ${ }^{[22-27]}$. So, this study was used a colloidal form nanosilver added to the acrylic monomer to form a mixture which mixed with the acrylic powder to form the specimens.

Respecting the color stability, it is the property of a material that allows color to be maintained over a period of time in a given environment. There were many factors responsible for the color changes of dental resin materials that are involving changes within the resin matrix and occurring at the interface of matrix and fillers are called intrinsic factors. In general, this intrinsic discoloration occurs with aging as a result of physical-chemical conditions (extrinsic factors) such as thermal and humidity changes. It has been reported that, both conventional and flexible resins suffered color alteration following aging due to intrinsic and extrinsic factors, it was founded that all resins exhibited a high $\Delta \mathrm{E}$ value of color alteration after accelerated aging ${ }^{[2,28,29]}$. In the present study the intrinsic discoloration of resin matrix was occurred due to incorporation of the Nano-silver component and the extrinsic due to thermal-humidity changes with accelerated aging.

In the study of Goiato et al., (2011) they were recorded that accelerated artificial aging produced significant color alteration in studied resins between 252 and $1008 \mathrm{~h}$ as the result of ultraviolet light, humidity and heat as accusative factors of polymer degradation ${ }^{[30]}$. The mechanism of these alterations were occurred when water molecules are absorbed by acrylic resin, they act like plasticizers to damage the material's mechanical resistance through the formation of microcracks related to absorption and hydrolytic degradation of the polymer, resulting in linkage cleavage and gradual deterioration of its infrastructure ${ }^{[31]}$. Oguz et al., (2007) were emphasis that even the control group showed a color change and the absorption may be the major cause of color change due to the polarity of the acrylic resin ${ }^{[32]}$. These results come in coincidence with the result of the present study. As regarding the effect of aging on color change of test specimens the result was recorded an increase in color alteration coordinated with the increased aging of incubation.

According to Andreotti et al., [2014] there were statistically significant differences in color stability of acrylic resin specific for ocular prosthesis with nanoparticles of zinc oxide, titanium dioxide and barium sulfate $(\mathrm{BaSO} 4)$ at weight concentrations of $1 \%, 2 \%$, and $2.5 \%$ after accelerated aging. All samples showed considerable color changes and the control and $\mathrm{BaSO} 4$ groups presented significantly higher values of color change compared with the other groups. They were concluded that, accelerated aging through ultraviolet light, humidity, and heat were a causative factor of polymer degradation that's altering the properties of acrylic resin. Incorporation of nanoparticles especially $2.5 \% \mathrm{TiO} 2$, helped in maintaining color stability and microhardness after aging ${ }^{[33]}$. These results were not coincidence at all with the results of the present study as the statistical analysis was demonstrated that, the accelerated aging associated with the concentration of NAg causing material degradation that interfered with color stability due to alteration of the material chemical structure under different conditions, such as storage time, temperature, and humidity.

Dramatically, it was observed that there were no statistically significance for group II (1\% NAg) and III ( $2 \% \mathrm{NAg}$ ) with the control (group I) in stage III (after $1008 \mathrm{H}$ ) of time, this may be interpreted as silver release from NAg specimens was occurred but the effect of staging was significant. Otherwise, there were significance of group IV (5\%) still persistent within the same stage III with all other groups of the stage, that's may be due large amount of silver content and long period of staging which need more time for releasing. Kumar and M“unstedt, (2005) were reported the Ag+ release rate increased with $\mathrm{Ag}$ concentration in the polymer 
and with the immersion time in water ${ }^{[27]}$. Yu et al, (2008) were incorporated silver nanoparticles in PMMA denture base, and noticed that the release of these nanoparticles was extremely slow during the test, with a very small fraction of Ag+ released in artificial saliva after 54 days ${ }^{[34]}$. Monteiro et al, (2012) were recorded after 120 days of storage in water; silver nanoparticles were located on the polymer surface, regardless of the amount of $\mathrm{Ag}$ added to the PMMA ${ }^{[17]}$.

Colorimetry is a branch of the science of color based on the digital expression of the color perceived from an object. In assessing chromatic difference, generally two color systems are used, namely: Munsell color system and Standard Commission international de L'Eclairage (CIE L*, $a^{*}$ and $b^{*}$ ) color system. The American Dental Association recommends the used of CIE $\mathrm{L}^{*}, \mathrm{a}^{*}$ and $\mathrm{b}^{*}$ color differential system ${ }^{[20]}$. The CIE $\mathrm{L}^{*}, \mathrm{a}^{*}$ and $\mathrm{b}^{*}$ color system uses the three parameters $\mathrm{L}^{*}, \mathrm{a}^{*}$ and $\mathrm{b}^{*}$ to define color and show the color difference quantitatively. $\Delta \mathrm{E}$ value which represents overall color difference between the two measurements in CIE L*, a* and $b^{*}$ color space is considered to be better indicator for evaluating the color stability of dental materials ${ }^{[28,35]}$. These principles were used in the study for assessment the chromatic differences between the different test groups.

For color evaluation of an object can be made based on subjective or objective methods. Subjective methods are based on visual observation, whereas in objective tests color parameters $\left(L^{*}, a^{*}, b^{*}\right)$ are quantified. $\mathrm{L}^{*}$ represents brightness on vertical axis from black to white. On horizontal planes, a* represents red on the positive side and green on the negative side, whereas $b^{*}$ represents yellow on the positive side and blue on the negative one. Color differences $(\Delta \mathrm{E})$ between two objects are evaluated using one object as control while the other is compared to it ${ }^{[36-38]}$. The value of $\Delta \mathrm{E}$ represents relative color changes that an observer might report for the materials after treatment or between time periods. Thus, $\Delta \mathrm{E}$ is more meaningful than the individual $\mathrm{L}^{*}, \mathrm{a}^{*}$ and $\mathrm{b}^{*}$ values ${ }^{[39,40]}$. The method was used for color evaluation in the study was a more qualified objective method for quantizing the $\Delta \mathrm{E}$ by using a double beam ultra-violet visible spectrophotometer to obtain diffuse reflectance data at every $5 \mathrm{~nm}$ between $400-700 \mathrm{~nm}$.

Goldstein and Schmitt, [1993] were reported that, when $\Delta \mathrm{E}$ is more than 3.7 is clinically unacceptable ${ }^{[41]}$. Although the clinical perceptibility and acceptability of color difference may vary, the interception of color difference would be related a range of values of $\Delta \mathrm{E}$ to perceptible color difference, values of $\Delta \mathrm{E}$ between 0 and 2 represent imperceptible color differences and clinically acceptable, whereas value of $\Delta \mathrm{E}$ in the range of 2-3 represent just perceptible color difference and $\Delta \mathrm{E}$ values of approximately 3.3 and above indicates an appreciable difference ${ }^{[42-44]}$. According to these input data, the results of the study can be interpreted in relation to the given clinical acceptance as the initial record of the mean $\Delta \mathrm{E}$ values for the control, $1 \%, 2 \%$ and $5 \%$ NAg groups $(0.40,1.37,1.59$ and $2.63)$, respectively were showed imperceptible $\Delta \mathrm{E}$ values and within the clinical accepted value of 3.3 or 3.7. In respecting the accelerated aging stages, the control groups were showed imperceptible $\Delta \mathrm{E}$ values less than 3.3 or 3.7 in all stages of aging. After 252 and $504 \mathrm{Hs}$ of aging with $1 \%$ and $2 \%$ $\mathrm{NAg}$ groups, the $\Delta \mathrm{E}$ values were showed less than 3.7 but in stage III $(1008 \mathrm{H})$ the $\Delta \mathrm{E}$ values were showed 3.76 and 3.81 respectively. An appreciable difference of $\Delta \mathrm{E}$ values more than 3.7 were recorded with $5 \% \mathrm{NAg}$ group in all aging stages except the initial which record $2.63 \Delta \mathrm{E}$ values.

It is important to emphasize that, there are other many factors influencing on the color alterations of acrylic resins such as poor cleaning of prosthesis, particles of the oral environment, material porosity and the polishing surface fabrication ${ }^{[4,45,46]}$. All these clinical and laboratory factors were caused a clinical implication from the results of this study as the difference between the oral environment and the in vitro conditions of the study must be 
considered. So that, this in vitro study was only attempted to simulate a clinical condition in which many other factors can affect color causing its limitations. Therefore, additional clinical studies must be performed to evaluate the NAg chemical interactions with acrylic resins and coloring factors in natural aging of oral cavity.

\section{CONCLUSIONS}

Within the limitations of this in vitro study, it can be concluded that: The silver nanoparticles incorporation within the acrylic denture base material can change its color. The higher incorporation of silver nanoparticles coincidence with the more color difference values $(\Delta \mathrm{E})$ of the acrylic resin denture. Accelerated aging was a causative factor of acrylic resin degradation and color alteration which exaggerated with the NAg incorporation and the long period of aging the more effectiveness alterations.

\section{Conflict of interest}

The author declares that there is no conflict of interest for the publication of this research.

\section{REFERENCES}

1. Hong G, Murata H, Li Y, Sadamori S, Hamada T. Influence of denture cleansers on the color stability of three types of denture base acrylic resin. J Prosthet Dent 2009; 101:205-13.

2. Goiato MC, Santos DM, Haddad MF, Pesqueira AA. Effect of accelerated aging on the microhardness and color stability of flexible resins for dentures. Braz Oral Res 2010; 24:114-9.

3. Goiato MC, Zuccolotti BC, Moreno A, Santos DM, Pesqueira AA, Dekon SFC. Colour change of soft denture liners after storage in coffee and coke. Gerodontology $2011 ; 28: 140-5$.

4. Imirzalioglu P, Karacaer O, Yilmaz B, Ozmen I. Color stability of denture acrylic resins and a soft lining material against tea, coffee, and nicotine. J Prosthodont 2010; 19:118-24.

5. Lai YL, Lui HF, Lee SY. In vitro color stability, stain resistance, and water sorption of four removable gingival flange materials. J Prosthet Dent 2003; 90:293-30.
6. Shimizu H, Kakigi M, Fujii J, Tsue F, Takahashi Y. Effect of surface preparation using ethyl acetate on the shear bond strength of repair resin to denture base resin. J Prosthodont 2008; 17:451-5.

7. Samiei M, Aghazadeh M, Lotfi M, Shakoei S, Aghazadeh Z, Pakdel SM. Antimicrobial efficacy of mineral trioxide aggregate with and without silver nanoparticles. Iran En$\operatorname{dod} \mathrm{J} 2013 ; 8: 166-170$.

8. Zhao L, Wang H, Huo K, Cui L, Zhang W, Ni H, Zhang Y, Wu Z, Chu PK. Antibacterial nano-structured titania coating incorporated with silver nanoparticles. Biomaterials 2011; 32:5706-5716.

9. Durner J, Stojanovic M, Urcan E, Hickel R, Reichl FX. Influence of silver nano-particles on monomer elution from lightcured composites. Dent Mater 2011; 27: 631- 636.

10. Corrêa JM, Mori M, Sanches HL, da Cruz AD, Poiate E Jr, Poiate IA. Silver nanoparticles in dental biomaterials. Int J Biomater 2015;2015:485275.

11. Tolaymat TM, El Badawy AM, Genaidy A, Scheckel KG, Luxton TP, Suidan M. An evidence-based environmental perspective of manufactured silver nanoparticle in syntheses and applications: a systematic review and critical appraisal of peer-reviewed scientific papers. Sci Total Environ 2010; 408: 999-1006.

12. Huang Z, Jiang X, Guo D, Gu N. Controllable synthesis and biomedical applications of silver nanomaterials. J Nanosci Nanotechnol 2011; 11: 9395-408.

13. Faunce T, Watal A. Nanosilver and Global Public Health: International Regulatory Issues. Nanomedicine (Lond) 2010; 5:617-32.

14. 14- Koichi Y, Harumi A, Takaichi Y. Color change capacity of dental resin mixed with silver methacrylate caused by light irradiation and heating. Dent Mater J 2009; 28:324-37.

15. Hamedi-Rad F, Ghaffari T, Rezaii F, Ramazani A. Effect of nanosilver on thermal and mechanical properties of acrylic base complete dentures. J Dent (Tehran) 2014; 11:495-505.

16. Yadav P, Mittal R, Sood VK, Garg R. Effect of incorporation of silane-treated silver and aluminum microparticles on strength and thermal conductivity of PMMA. J Prosthodont 2012; 21:546-51.

17. Monteiro DR, Gorup LF, Takamiya AS, de Camargo ER, Filho AC, Barbosa DB. Silver distribution and release 
from an antimicrobial denture base resin containing silver colloidal nanoparticles. J Prosthodont 2012; 1:7-15.

18. Commission Internationale de L'Eclairagc. Colorimetry: Official Recommendations of the International Commission on Illumination. 2nd ed. Paris: Bureau Central de la CIE; 1985.

19. Chen X, Schluesener HJ. Nanosilver: a nanoproduct in medical application. Toxicol Lett 2008; 176:1-12.

20. Majdalawieh A, Kanan MC, El-Kadri O, Kanan SM. Recent advances in gold and silver nanoparticles: synthesis and applications. J Nanosci Nanotechnol 2014; 14: 4757-80.

21. Chaloupka K, Malam Y, Seifalian AM. Nanosilver as a new generation of nanoproduct in biomedical applications. Trends Biotechnol 2010; 28:580-8.

22. Morones JR, Elechiguerra JL, Camacho A, Holt K, Kouri JB, Ramírez JT, Yacaman MJ. The bactericidal effect of silver nanoparticles. Nanotechnology 2005; 16:2346-53.

23. Fan C, Chu L, Rawls H, Norling B, Cardenas H, Whang K. Development of an antimicrobial resin- a pilot study. Dent Mater 2011; 27: 322-28.

24. Cheng YJ, Zeiger DN, Howarter JA, Zhang X, Lin NJ, Antonucci JM, Lin-Gibson S. In situ formation of silver nanoparticles in photocross-linking polymers. J Biomed Mater Res B Appl Biomater 2011; 97:124-31.

25. Mahross HZ, Baroudi K. Effect of silver nanoparticles incorporation on viscoelastic properties of acrylic resin denture base material. Eur J Dent 2015; 9:207-12.

26. Li F, Weir MD, Chen J, Xu HK. Comparison of quaternary ammonium-containing with nano-silver-containing adhesive in antibacterial properties and cytotoxicity. Dent Mater 2013; 29: 450-61.

27. Kumar R, M“unstedt H. Silver ion release from antimicrobial polyamide/silver composites. Biomaterials 2005; 26:2081-2088.

28. Assuncao WG, Barao VA, Pita MS, Goiato MC. Effect of polymerization methods and thermal cycling on color stability of acrylic resin denture teeth. J Prosthet Dent 2009; 102:385-92.

29. Mundim FM, Garcia Lda F, Pires-de-Souza Fde C. Effect of staining solutions and repolishing on color stability of direct composites. J Appl Oral Sci2010; 18:249-54.

30. Goiato MC, Santos DM, Souza JF, Moreno A, Pesqueira AA. Chromatic stability of acrylic resins of artificial eyes submitted to accelerated aging and polishing. J Appl Oral Sci 2010; 18:641-5.

31. Goiato MC, Nóbrega AS, dos Santos DM, Andreotti AM, Moreno A. Effect of different solutions on color stability of acrylic resin-based dentures. Braz Oral Res 2014; 28(1).

32. Oguz S, Mutluay MM, Dogan OM, Bek B. Color change evaluation of denture soft lining materials in coffee and tea. Dent Mater J 2007; 26:209-16.

33. Andreotti AM, Goiato MC, Moreno A, Nobrega AS, Pesqueira AA, dos Santos DM. Influence of nanoparticles on color stability, microhardness, and flexural strength of acrylic resins specific for ocular prosthesis. Int J Nanomedicine 2014; 10:5779-87.

34. Yu RY, Zhou YS, Feng HL, Liu XY. Silver-ion release and particle distribution of denture base resin containing nanometer-sized silver-supported antimicrobial agent. Zhonghua Kou Qiang Yi Xue Za Zhi 2008; 43:54-56

35. Heydecke G, Zhang F, Razzoog ME. In vitro color stability of double-layer veneers after accelerated aging. J Prosthet Dent 2001; 85; 551-557.

36. Villalta P, Lu H, Okte Z, Garcia-Godoy F, Powers JM. Effects of staining and bleaching on color change of dental composite resins. J Prosthet Dent 2006; 95:137-42.

37. Subramanya JK, Muttagi S. In vitro color change of three dental veneering resins in tea, coffee and tamarind extract. J Dent (Tehran) 2011; 8:138-45.

38. Silva PM, Acosta EJ, Jacobina M, Pinto Lde R, Porto VC. Effect of repeated immersion solution cycles on the color stability of denture tooth acrylic resins. J Appl Oral Sci 2011; 19:623-7.

39. Powers JM, Barakat MM, Ogura H. Color and optical properties of posterior composites under accelerated aging. Dent Mater J 1985; 4:62-7.

40. Lim BS, Moon HJ, Baek KW, Hahn SH, Kim CW. Color stability of glass ionomer and polyacid-modified resin based composites in various environmental solutions. Am J Dent 2001; 14:241-6.

41. Goldstein GR, Schmitt GW. Repeatability of a specially designed intraoral colorimeter. J Prosthet Dent 1993; 69:616-9.

42. Canay S, Cehreli MC. The effect of current bleaching agents on the color of light polymerized composites in vitro. J Prosthet Dent 2003; 89:474-8. 
43. Schulze KA, Marshall SJ, Gansky SA, Marshall GW. Color stability and hardness in dental composites after accelerated aging. Dent Mater 2003; 19:612-9.

44. Koishi Y, Tanoue N, Matsumura H, Atsuta M. Color reproducibility of a photo-activated prosthetic composite with different thickness. J Oral Rehabil 2001; 28:799-804.
45. Waliszewski M. Restoring dentate appearance: a literature review for modern complete denture esthetics. J Prosthet Dent 2005; 93:386-94.

46. Keyf F, Etikan I. Evaluation of gloss changes of two denture acrylic resin materials in four different beverages. Dent Mater 2004; 20:244-51. 